Formatif: Jurnal Ilmiah Pendidikan MIPA

Vol. 9, No. 2, Juni 2019, pp. 107-116

p-ISSN: 2088-351X

e-ISSN: $2502-5457$

DOI: http://dx.doi.org/10.30998/formatif.v9i2.3339

\title{
Problem Based Learning Implementation to Increase the Students' Conceptual Understanding of Elasticity
}

\author{
Implementasi Problem Based Learning dalam Meningkatkan Pemahaman Konsep \\ Siswa pada Topik Elastisitas
}

\author{
Muhammad Reyza Arief Taqwa (*) \\ Universitas Negeri Malang \\ Lugy Rivaldo \\ Universitas Jambi \\ Revnika Faizah \\ Universitas Negeri Yogyakarta
}

Received: February 5, 2019

Revised: March 20, 2019

Accepted: March 22, 2019

\begin{abstract}
This study aims to determine the effectiveness of the implementation of problem based learning in elasticity and Hooke's law. The design of this study is the Embedded Experimental Model with a mixed method approach. Implementation was carried out at SMAN 5 Jambi in 34 students of Class XI IPA in the 2018/2019 school year. From the results of the analysis obtained there was an increase in conceptual understanding scores from 42.31 atpretest became 57.01 at posttest. The results of different tests using paired sample $t$-test were obtained $t=-4,901$ (sig. $0,000)$ so it can be concluded that the pretest and posttest scores is differ significantly. Obtained the value of $\mathrm{N}$-gain $=0.255$ and effect size $(\mathrm{d})=$ 0.930 shows an increase in the medium category and there is the influence of the implementation of the problem based learning model that is strong enough to increase understanding of students' concepts. Although students and teachers experience obstacles in implementing problem based learning learning models, this learning must continue to be carried out with improvement so students are accustomed to construct their own knowledge.
\end{abstract}

Keywords: Problem Based Learning, conceptual understanding, elasticity

(*) Corresponding Author: $\quad$ Reyza.arief.fmipa@um.ac.id; +62 83834315454

How to Cite: Taqwa, M. R. A., Rivaldo, L., \& Faizah, R. (2019). Problem based learning implementation to increase the students' conceptual understanding of elastisity. Formatif: Jurnal Ilmiah Pendidikan MIPA, 9 (2): 107-116. http://dx.doi.org/10.30998/formatif.v9i2.3339

\section{PENDAHULUAN}

Fisika merupakan salah satu mata pelajaran dengan cakupan pengetahuan yang mendasari beberapa disiplin ilmu lain karena mengkaji beberapa konsep fundamental. Salah satu tujuan penting pembelajaran fisika adalah tercapainya pemahaman konsep yang baik sehingga siswa dapat menggunakan pemahaman tersebut untuk memecahkan bermacam persoalan dan menjelaskan beragam fenomena fisis (Taqwa et al, 2017). Namun secara praktis, kontras dengan temuan beberapa peneliti yang menunjukkan 


\section{Formatif: Jurnal Ilmiah Pendidikan MIPA}

Vol. 9, No. 2, Juni 2019, pp. 107-116

p-ISSN: 2088-351X

e-ISSN: 2502-5457

DOI: http://dx.doi.org/10.30998/formatif.v9i2.3339

bahwa pemahaman siswa masih cenderung rendah sehingga sering kali gagal dalam memecahkan persoalan yang mereka temui. Kesulitan tersebut sudah banyak ditemukan oleh peneliti, terutama pada topik mekanika, seperti vektor (Aguirre, 1988; Aguirre \& Rankin, 1989), kinematika (Antwi et al, 2011; Jugueta et al, 2012), dinamika partikel (Adair, 2013; Thornton \& Sokoloff, 1998; White, 1983), dinamika rotasi (Close et al, 2013; Rimoldini \& Singh, 2005; Robinson, 2014), usaha dan energi (Bezen, Bayrak, \& Aykutlu, 2016), momentum dan impuls (kaniawati, 2017; Saifullah et al, 2017; Singh \& Rosengrant, 2016), serta elastisitas dan hukum Hooke (Azizah et al, 2015).

Elastisitas merupakan bahasan yang cukup penting dengan keterkaitannya dalam membangun pengetahuan lain. Tidak seperti bagian mekanika yang lain (seperti kinematika dan dinamika), pokok bahasan elastisitas jarang mendapat perhatian lebih dari peneliti. Padahal siswa sering mengalami kesulitan dalam menyelesaikan soal-soal elastisitas (Yulianawati et al, 2018) dan sering kali mengalami miskonsepsi (Hidayati et $a l$, 2014). Hal tersebut terjadi karena siswa sering kali membangun pengetahuan yang keliru dari pengamatan yang mereka alami di kehidupan mereka. Pengetahuan keliru yang mereka peroleh sendiri justru lebih dipercaya dan mengakar sehingga bersifat retensi (Berek et al, 2016). Oleh karena itu, perlu upaya pembelajaran yang dapat memfasilitasi siswa untuk dapat membangun pengetahuan yang benar dan menggantikan pemahaman yang keliru. Hal tersebut harus diupayakan dengan pembelajaran yang bermakna, tidak dapat hanya sekadar melalui transfer pengetahuan dengan metode ceramah saja. Salah satu model pembelajaran yang dapat diterapkan adalah model pembelajaran Problem Based Learning (PBL).

Model pembelajaran PBL merupakan salah satu model pembelajaran dengan menganut teori belajar konstruktivisme (Maryati, 2018; Prasetyanti et al, 2016; Sunaryo, 2014) yang menuntut siswa melakukan pengamatan terhadap realitas dalam kehidupan sehari-hari. Selain itu, siswa dituntut untuk memecahkan permasalahan yang dihadapi dengan menggunakan pengetahuan yang mereka miliki. Dalam pembelajaran PBL, siswa dituntut untuk lebih aktif dalam membangun pengetahuan sesuai dengan tuntutan Kurikulum 2013 agar pembelajaran tidak terpusat pada guru. Kegiatan penyeledikan yang dilakukan dalam model pembelajara PBL juga menggiring siswa untuk menemukan, memverifikasi, dan membangun pengetahuan mereka sendiri sehingga pengetahuan yang mereka miliki lebih bermakna dan tersimpan pada memori jangka panjangnya (long term memory). Dalam artikel ini akan membahas terkait efektivitas implementasi model pembelajaran terhadap peningkatan pemahaman konsep yang dimiliki oleh siswa. Topik yang diangkat hanya difokuskan pada elastisitas dan hukum Hooke.

\section{METODE}

Penelitian ini bertujuan untuk mengetahui efektivitas implementasi model pembelajaran Problem Based Learning terhadap peningkatan pemahaman konsep elastisitas dan hukum Hooke. Penelitian ini menggunakan desain penelitian Embedded Experimental Model (Creswell, 2014) dengan pendekatan penelitian mixed method. Penelitian ini dilakukan pada 34 siswa Kelas XI IPA di SMAN 5 Kota Jambi pada tahun ajaran 2018/2019. Desain penelitian secara umum dapat dilihat pada Gambar 1. 
Formatif: Jurnal Ilmiah Pendidikan MIPA

Vol. 9, No. 2, Juni 2019, pp. 107-116

p-ISSN: 2088-351X

e-ISSN: 2502-5457

DOI: http://dx.doi.org/10.30998/formatif.v9i2.3339

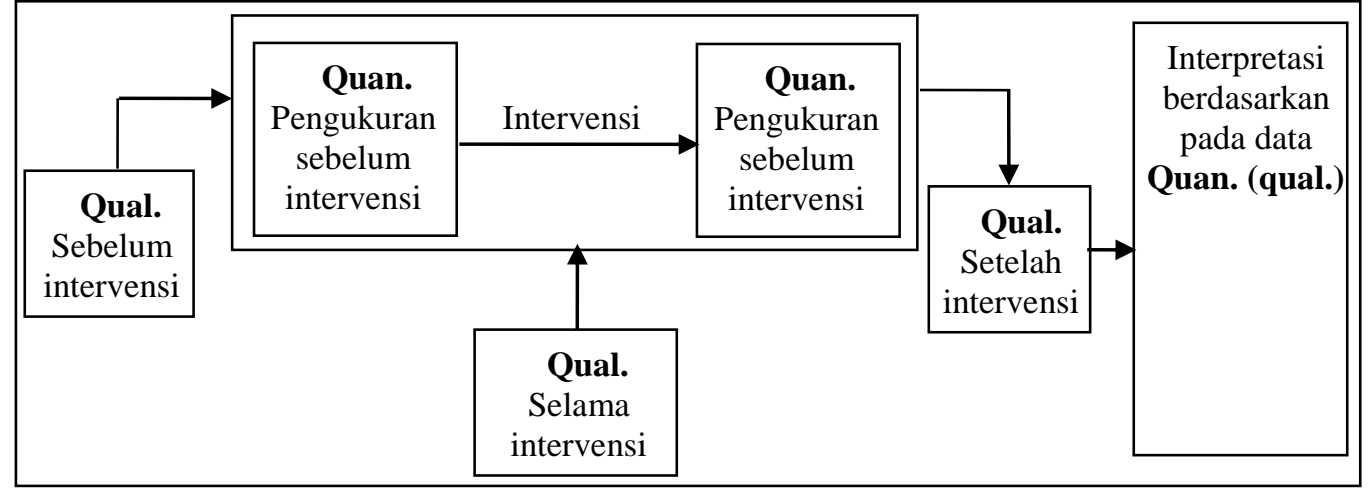

Gambar 1. Desain Penelitian

Kegiatan awal penelitian dilakukan dengan observasi pembelajaran, dengan tujuan untuk melihat karakteristik peserta didik dan kemampuan awal yang dimiliki. Dalam kegiatan penelitian, sebelum dan setelah intervensi siswa diberikan 13 soal tes pilihan ganda beralasan. Soal pretest dan posttest merupakan soal yang sama. Soal tersebut telah divalidasi oleh ahli dan diuji lapangan kepada 85 siswa untuk menentukan kelayakan instrumen secara empirik. Dari hasil uji empirik diperoleh 13 soal yang layak untuk digunakan dari total 18 soal. Adapun topik yang diujikan dan data hasil uji empirik ditunjukkan oleh Tabel 1.

Tabel 1. Tujuan Butir Soal dan Hasil Uji Empirik

\begin{tabular}{|c|c|c|c|c|c|}
\hline Topik yang Diujikan & $\begin{array}{l}\text { No } \\
\text { Soal }\end{array}$ & $\begin{array}{l}\text { Koefesien } \\
\text { Pearson }\end{array}$ & $\begin{array}{c}\text { Daya } \\
\text { Pembeda }\end{array}$ & $\begin{array}{l}\text { Tingkat } \\
\text { Kesukaran }\end{array}$ & $\begin{array}{c}\text { Koef. } \\
\text { Cronbach } \\
\text { Alpha }\end{array}$ \\
\hline \multirow[t]{4}{*}{ Tegangan $(\sigma)$} & 1 & 0,423 & 0,43 & 0,46 & \multirow[t]{18}{*}{0,812} \\
\hline & $2^{*}$ & 0,124 & 0,18 & 0,17 & \\
\hline & 3 & 0,328 & 0,30 & 0,34 & \\
\hline & $4^{*}$ & 0,199 & 0,16 & 0,24 & \\
\hline \multirow[t]{4}{*}{ Regangan (e) } & 5 & 0,363 & 0,33 & 0,45 & \\
\hline & $6^{*}$ & 0,211 & 0,22 & 0,14 & \\
\hline & 7 & 0,347 & 0,33 & 0,44 & \\
\hline & 8 & 0,236 & 0,28 & 0,25 & \\
\hline \multirow[t]{3}{*}{ Modulus Young (E) } & 9 & 0,351 & 0,41 & 0,31 & \\
\hline & 10 & 0,289 & 0,23 & 0,22 & \\
\hline & 11 & 0,328 & 0,33 & 0,37 & \\
\hline \multirow[t]{3}{*}{ Hukum Hooke } & 12 & 0,429 & 0,35 & 0,62 & \\
\hline & $13^{*}$ & 0,201 & 0,25 & 0,21 & \\
\hline & 14 & 0,347 & 0,30 & 0,36 & \\
\hline \multirow[t]{4}{*}{ Rangkaian Pegas } & $15^{*}$ & 0,164 & 0,20 & 0,33 & \\
\hline & 16 & 0,548 & 0,45 & 0,58 & \\
\hline & 17 & 0,351 & 0,23 & 0,42 & \\
\hline & 18 & 0,289 & 0,34 & 0,35 & \\
\hline
\end{tabular}

*soal tidak digunakan

Berdasarkan Tabel 1 terdapat lima soal yang tidak digunakan dalam penelitian karena tidak memenuhi kriteria butir soal yang baik, yakni soal nomor 2, 4, 6, 13, dan 15 . Hal tersebut diputuskan karena nilai koefesien $r_{\text {hitung }}$ lebih kecil dari $r_{\text {tabel }}$ yakni 0,213 


\section{Formatif: Jurnal Ilmiah Pendidikan MIPA}

Vol. 9, No. 2, Juni 2019, pp. 107-116

p-ISSN: 2088-351X

e-ISSN: 2502-5457

DOI: http://dx.doi.org/10.30998/formatif.v9i2.3339

untuk $\mathrm{N}=85$. Berdasarkan nilai Crobach's Alpha maka dapat dikatakan bahwa soal yang digunakan merupakan soal yang andal karena bernilai lebih dari 0,70 (Bernardi, 1994; Janti, 2014). Sebagai pendukung, perlu pula diketahui indeks pembedaan dan tingkat kesukaran butir soal. Berdasarkan daya pembeda terdapat soal dengan daya pembeda jelek (soal nomor 2, 4, dan 15), cukup (soal nomor 3, 6, 8, 10,13, 14, dan 17), baik (soal nomor 5, 7, 11, 12, dan 13), dan sangat baik (soal nomor 1, 9, dan 16) (Suruchi \& Rana, 2014). Berdasarkan tingkat kesukaran butir soal terdapat soal sulit (soal nomor 2, 4, 6, 8, 10, dan 13), sedang (soal nomor 1, 3, 5, 7, 9, 11, 12, 14, 15, 16, 17, dan 18) (Suruchi \& Rana, 2014).

Data yang diperoleh dari hasil penelitian ini merupakan data kuantitatif dan kualitatif. Data kuantitatif diperoleh dari instrumen tes pemahaman konsep sedangkan data kualitatif diperoleh dari alasan jawaban siswa dan kegiatan observasi. Analisis data kuantitatif dilakukan dengan cara menentukan statistik desktiptif, kemudian melakukan uji beda dengan menggunakan paired sample t-test. Namun sebelum dilakukan uji beda paired sample t-test terlebih dahulu dilakukan uji normalitas data yang mana dalam penelitian ini dilakukan dengan menentukan nilai Skewness, karena nilai Skewness diantara -1 hingga +1 menunjukkan bahwa set data mendekati terdistribusi normal (Leechet al, 2005). Setelah diketahui bahwa data terdistribusi normal maka dihitung nilai $N$-gain (Bao, 2006) dan effect size (d) (Leechet al, 2005). Untuk data kualitatif, analisis data dilakukan dengan mengolah perolehan data yang kemudian disajikan dalam bentuk paparan secara deskriptif. Paparan data yang dimaksud lebih ditekankan pada pemahaman konsep siswa.

\section{HASIL DAN PEMBAHASAN}

Hasil

Dalam artikel ini akan dipaparkan perubahan pemahaman konsep siswa pada topik elastisitas dan hukum Hooke dari pretest ke posttest. Berdasarkan data skor pemahaman konsep yang telah diperoleh, data diolah dan disajikan dalam statistik deskriptif. Adapaun statistik deskriptif dari skor pemahaman konsep siswa ditunjukkan oleh Tabel 2.

Tabel 2. Hasil Statistik Deskriptif

\begin{tabular}{clll}
\hline No & Ukuran Deskriptif & Pretest & Posttest \\
\hline 1 & Minimum & 7,69 & 23,08 \\
2 & Maksimum & 69,23 & 100,00 \\
3 & Modus & 46,15 & 61,54 \\
4 & Median & 46,15 & 61,54 \\
5 & Mean & 42,31 & 57,01 \\
6 & Simpangan Baku & 2,11 & 3,31 \\
7 & Varians & 151,51 & 373,39 \\
8 & Skewness & $-0,707$ & 0,269 \\
\hline
\end{tabular}

Berdasarkan Tabel 2 dapat dilihat bahwa rata-rata skor pemahaman konsep siswa adalah berbeda dan meningkat dari 42,31 pada saat pretest menjadi 57,01 pada saat posttest. Untuk menentukan apakah skor pemahaman konsep siswa meningkat secara signifikan atau tidak, maka perlu dilakukan uji beda dengan paired sample t-test. Namun sebelum melakukan uji paired sample t-test, terlebih dahulu dipastikan bahwa data 


\section{Formatif: Jurnal Ilmiah Pendidikan MIPA}

Vol. 9, No. 2, Juni 2019, pp. 107-116

p-ISSN: 2088-351X

e-ISSN: 2502-5457

DOI: http://dx.doi.org/10.30998/formatif.v9i2.3339

pretest dan posttest terdistribusi normal. Berdasarkan nilai Skewness data pretest yakni sebesar -0,707 dan data posttest sebesar 0,269 maka dapat dikatakan bahwa kedua set data terdistribusi normal (Leech et al., 2005) sehingga uji beda paired sample t-test dapat dilakukan.

Berdasarkan hasil uji beda paired sample t-test diperoleh bahwa $\mathrm{t}=-4,901$ (sig. $=0,000)$ sehingga dapat disimpulkan bahwa terdapat perbedaan yang signifikan antara skor pretest dan posttest. Besar peningkatan skor dapat dilihat dari nilai $\mathrm{N}$-gain yakni sebesar 0,255. Nilai tersebut berada pada kategori peningkatan rendah (Hake, 1998). Kemudian untuk mengetahui kekuatan perbedaan antara skor pretest dan posttest setelah implementasi model pembelajaran Problem Based Learning dapat dilihat dari nilai effect size (d) yakni sebesar 0,930. Nilai tersebut menunjukkan perbedaan besar (kuat) antara skor pretest dan posttest setelah implementasi model pembelajaran Problem Based Learning.

Proses pembelajaran yang dilakukan secara umum dapat meningkatkan pemahaman konsep siswa. Namun, terdapat satu soal yang mengalami peningkatan skor signifikan setelah kegiatan pembelajaran berlangsung yakni soal nomor 12. Soal tersebut terkait konsep hukum Hooke. Siswa diminta untuk menentukan perubahan panjang pegas ketika pegas diberi gaya $\mathrm{F}$ dari kedua sisi. Adapun soal yang diberikan ketika pretest dan posttest ditunjukkan Gambar 2.

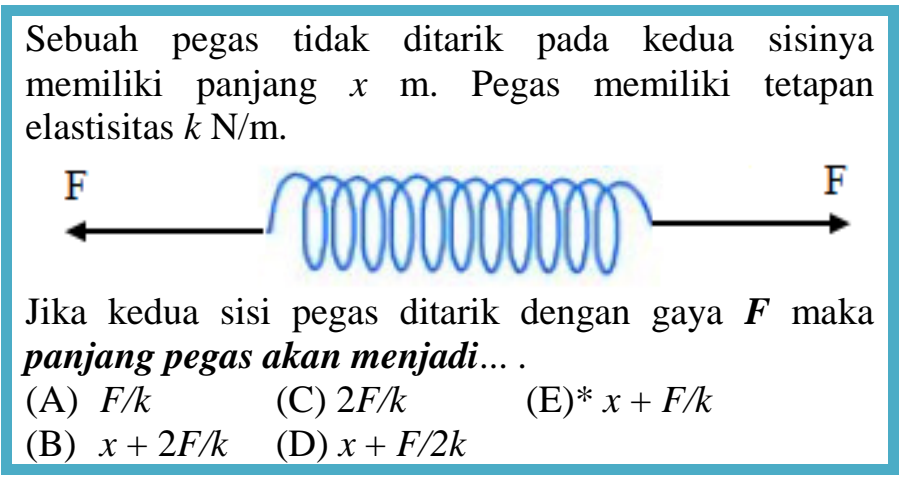

Gambar 2. Soal Pemahaman Konsep

Dalam menjawab soal tersebut, hanya sedikit siswa yang menjawab dengan benar. Adapun distribusi pergeseran jawaban siswa dalam menjawab soal nomor 12 ditunjukkan Tabel 3.

Tabel 3. Crosstabulation Pergeseran Jawaban Pretest ke Posttest Siswa

\begin{tabular}{ccccccc} 
& \multicolumn{7}{c}{ Posttest } & \multirow{2}{*}{ Total } \\
\cline { 2 - 6 } & $\mathbf{A}$ & $\mathbf{B}$ & $\mathbf{C}$ & $\mathbf{D}$ & $\mathbf{E}^{*}$ & \\
\hline $\mathbf{A}$ & 0 & 0 & 0 & 0 & 2 & 2 \\
\hline $\mathbf{B}$ & 0 & 0 & 0 & 0 & 19 & 19 \\
\hline $\mathbf{C}$ & 2 & 0 & 0 & 0 & 10 & 12 \\
\hline $\mathbf{D}$ & 0 & 0 & 0 & 0 & 0 & 0 \\
\hline $\mathbf{E}$ & 0 & 0 & 0 & 0 & 1 & 1 \\
\hline Total & 2 & 0 & 0 & 0 & 32 & 34 \\
\hline
\end{tabular}

Dari tabel tersebut, tampak bahwa hanya satu $(2,95 \%)$ siswa yang memilih opsi E pada saat pretest dan siswa tersebut tetap memilih jawaban E pada saat posttest. Pergeseran jawaban siswa yang keliru ketika pretest kemudian benar ketika posttest 


\section{Formatif: Jurnal Ilmiah Pendidikan MIPA}

Vol. 9, No. 2, Juni 2019, pp. 107-116

p-ISSN: 2088-351X

e-ISSN: 2502-5457

DOI: http://dx.doi.org/10.30998/formatif.v9i2.3339

diantaranya, $2(5,88 \%)$ siswa memilih opsi A ketika pretest kemudian memilih opsi $\mathrm{E}$ ketika posttest, $19(55,88 \%)$ siswa memilih opsi B ketika pretest kemudian memilih opsi E ketika posttest, $12(35,29 \%)$ siswa memilih opsi C ketika pretest kemudian memilih opsi E ketika posttest. Selain itu, terdapat dua $(5,88 \%)$ siswa yang memilih opsi C ketika pretest kemudian memilih opsi A ketika posttest.

\section{Pembahasan}

Berdasarkan hasil analisis data yang diperoleh, model pembelajaran Problem Based Learning pada topik elastisitas dan hukum Hooke dapat meningkatkan pemahaman konsep siswa. Model pembelajaran Problem Based Learningini diklaim dapat meningkatkan aktivitas belajar siswa (Agustin, 2013; Baksir, Mayub, \& Hanisa, 2017; Velly, 2017) dan mampu membuat siswa lebih aktif untuk mencari pengetahuan sendiri (Setyorini, Sukiswo, \& Subali, 2011). Dalam implementasi model pembelajaran Problem Based Learning ini masih mengalami kesulitan karena siswa di SMAN 5 Jambi lebih terbiasa belajar dengan metode ceramah. Hal ini dikarenakan siswa hanya dituntut untuk mendengarkan penjelasan yang diberikan oleh guru sehingga siswa tidak dituntut untuk mandiri.

Kendati metode ceramah lebih disukai oleh siswa dan penyampaian materi lebih sederhana, cepat, dan ringkas, namun metode ceramah tidak cocok untuk membangun pengetahuan siswa menjadi body of knowledge yang koheren. Terutama untuk siswa yang mengalami miskonsepsi, metode pembelajaran yang hanya sekadar transfer informasi tidak akan mampu mengubah konsepsi siswa dalam jangka waktu yang panjang. Hal tersebut dikarenakan miskonsepsi bersifat retensi (Docktor \& Mestre, 2014). Hal tersebut berbeda dengan pembelajaran yang menuntut siswa untuk menemukan pengetahuannya sendiri. Siswa akan lebih lama menyimpan pengetahuannya jika mereka aktif menemukan dan membangun pengetahuannya sendiri, seperti temuan Kartika et. al. (2014). Kendati demikian siswa lebih menyukai belajar dengan metode ceramah karena tidak terlalu banyak tuntutan ketika pembelajaran.

Dalam implementasi model pembelajaran Problem Based Learningsiswa diajak untuk memahami fisika sesuai dengan hakikat keilmuan, belajar sebagaimana ilmuan membangun pengetahuan. Namun ketika penerapan di kelas, terdapat kesulitan pada penerapan model Problem Based Learning terutama pada tahapan penyelidikan. Terdapat beberapa siswa yang mengambil data dengan keliru. Pengambilan data dengan keliru akan menggiring siswa pada simpulan yang keliru pula, sehingga pemecahan masalah yang diperoleh menjadi kurang tepat.

Bukan hanya pada siswa, kesulitan juga dialami oleh guru dalam mengimplementasikan model pembelajaran Problem Based Learning. Untuk benar-benar mengimplementasikan model pembalajaran Problem Based Learning secara baik diperlukan alokasi waktu yang cukup lama. Selain itu, seperti temuan Tyas (2017) pada tahap orientasi masalah, guru mengalami kesulitan dalam menentukan masalah yang tepat untuk dapat menstimulus aktivitas diskusi siswa.

Dalam penelitian ini secara umum memang berhasil meningkatkan pemahaman konsep siswa. Namun demikian $\mathrm{N}$-gain yang diperoleh masih tergolong sedang (Hake, 1998) yakni sebesar 0,255. Pengubahan cara belajar dengan menuntut siswa lebih aktif ini harus terus dilakukan agar siswa siap menghadapi permasalahan yang lebih sulit ke depannya. Mengubah cara belajar agar sesuai proporsi tuntutan luaran yang diharapkan tetap perlu meskipun pada awalnya siswa mengalami kesulitan.

Peningkatan pemahaman konsep siswa ditandai dengan peningkatan skor tes. Dari beberapa soal yang diberikan pada saat tes, terdapat satu butir soal dengan 


\section{Formatif: Jurnal Ilmiah Pendidikan MIPA}

Vol. 9, No. 2, Juni 2019, pp. 107-116

p-ISSN: 2088-351X

e-ISSN: 2502-5457

DOI: http://dx.doi.org/10.30998/formatif.v9i2.3339

peningkatan yang signifikan yakni soal nomor 12 . Dalam menjawab soal tersebut hanya satu $(2,94 \%)$ siswa yang menjawab soal dengan benar ketika pretest dan meningkat menjadi $32(94,12 \%)$ siswa yang menjawab dengan benar ketika posttest. Kekeliruan yang dialami oleh siswa yang menjawab $\mathrm{B}$ adalah menganggap bahwa ketiga pegas ditarik dengan gaya $\mathrm{F}$ pada kedua sisi, maka resulta gaya yang bekerja pada pegas adalah $2 F$. Siswa yang berpikiran demikian bukan berarti mengalami miskonsepsi. Hanya saja, siswa lebih "mengangkat" konsepsi yang salah yakni "pegas akan mengalami perubahan panjang yang lebih besar jika ditarik dari dua sisi dibandingkan dengan satu sisi". Pemikiran tersebut sekilas benar, namun perlu diverifikasi dengan pengetahuan lain untuk memastikan apakah pemikiran tersebut benar.

Dalam pembelajaran, untuk menggiring pemahaman siswa pada konsep yang benar, dilakukan dengan menguatkan konsep hukum III Newton. Penting menyadari bahwa gaya merupakan hasil interaksi antara dua objek. Penjelasan konsep soal nomor 12 dibantu dengan Gambar 3 untuk menunjukkan bahwa gaya selalu hasil interaksi antar objek. Berdasarkan skema tersebut, tampak bahwa jika pegas ditarik oleh tangan akan menimbulkan gaya tarikan tangan tangan pada pegas $\left(\boldsymbol{F}_{\mathrm{TP}}\right)$ yang mana merupakan hasil interaksi antara tangan dan pegas. Lalu apa yang terjadi jika tangan menarik pegas? Jelas tangan akan merasa "tertarik" oleh pegas. Gaya itu yang kita namakan sebagai $\boldsymbol{F}_{\mathrm{PT}}$, yakni gaya tarikan pegas pada tangan. $\boldsymbol{F}_{\text {PT }}$ timbul akibat interaksi antara pegas dengan tangan pula (catatan: $\boldsymbol{F}_{\mathrm{TP}}$ dan $\boldsymbol{F}_{\mathrm{PT}}$ merupakan gaya yang timbul secara simultan selama kedua benda berinteraksi, baik tarik-menarik maupun tolak-menolak). Lalu bagaimana dengan tarikan pada salah satu sisinya? Untuk menjawab soal tersebut, coba kita arahkan pemikiran siswa dengan pertanyaan, "Apa yang terjadi jika pegas berada di atas lantai licin kemudian kalian tarik di salah satu sisinya? Dapatkah pegas meregang? Tentu tidak". Yang harus dilakukan agar pegas dapat meregang adalah dengan menahan salah satu sisi, ketika sisi lain diberi gaya. Menahan salah satu sisi bertujuan agar "posisi" ujung pegas tidak mengalami perpindahan meskipun ujung pada sisi lain diberi gaya. Bagian "penahan" ini (dalam kasus ini dinding) akan memberikan gaya yang sama besar namun berlawanan arah dengan gaya tarik $\boldsymbol{F}_{\mathrm{TP}}$. Gaya tersebut selanjutkan dilabelkan sebagai $\boldsymbol{F}_{\mathrm{DP}}$, yakni gaya tarikan dinding pada pegas. Sebagai hasil interaksi pegasdinding, maka ketika dinding menarik pegas, secara simultan pegas akan menarik dinding dengan gaya $\boldsymbol{F}_{\mathrm{PD}}$. Dari pola pikir demikian, siswa dapat diarahkan untuk berpikir bahwa $\boldsymbol{F}_{\mathrm{TP}}$ dan $\boldsymbol{F}_{\mathrm{DP}}$ adalah gaya yang sama besar namun berlawanan arah. Sehingga ketika sebuah pegas ditarik dengan gaya $\boldsymbol{F}$ dengan salah satu sisi ditahan, maka sisi yang ditahan tersebut sebenarnya memberikan gaya sebesar $\boldsymbol{F}$ pula. Namun demikian gaya total yang meregangkan pegas adalah sebesar $\boldsymbol{F}$.

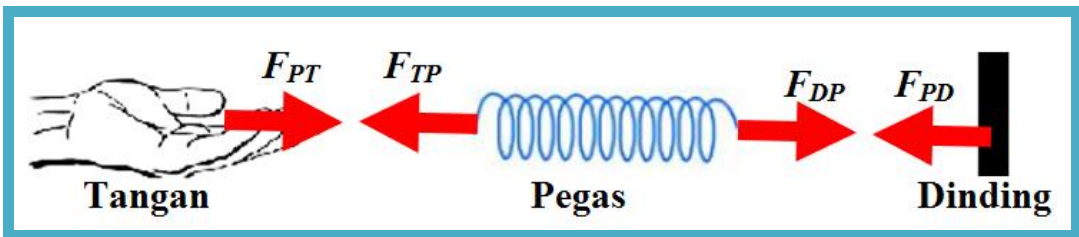

Gambar 3. Penjelasan Gaya Selalu Sebagai Hasil Interaksi Dua Objek

Resource pemahaman tersebut merupakan implikasi hukum III Newton yang sudah diperoleh oleh siswa sejak SMP. Namun pengetahuan relevan yang telah dimiliki siswa sering kali gagal teraktivasi ketika menemui permasalahan fisis (Taqwa \& Pilendia, 2018; Taqwa et al, 2019). Siswa lebih sering menggunakan ilmu yang lebih melekat pada pemikiran mereka untuk menyelesaikan persoalan. Sayangnya, siswa sering kali terburuburu dalam memutuskan resource dan pemahaman yang akan mereka pakai dalam 


\section{Formatif: Jurnal Ilmiah Pendidikan MIPA}

Vol. 9, No. 2, Juni 2019, pp. 107-116

p-ISSN: 2088-351X

e-ISSN: 2502-5457

DOI: http://dx.doi.org/10.30998/formatif.v9i2.3339

menyelesaikan persoalan tanpa diverifikasi terlebih dahulu dengan pengetahuanpengetahuan lain. Oleh karena itu, menjadi penting sebagai guru untuk melatih siswa agar dapat memahami dan menggunakan konsep fisika secara utuh, bukan secara parsial karena pengetahuan yang terpotong-potong (Hammer, 2000; Saputri et al, 2019) akan menyulitkan siswa memahami fisika. Namun demikian, sering kali konsep ilmiah yang benar justru tidak sesuai dengan konsepsi yang telah dimiliki siswa sebelum pembelajaran. Selain itu, siswa terkadang telah memiliki konsep benar yang berlaku khusus pada suatu konteks, namun sering kali digeneralisasi dalam konteks lain yang tidak sesuai. Hal tersebut dapat diatasi dengan menyajikan fenomena yang mampu "menyangkal" konsepsi keliru yang diyakini oleh siswa atau memaparkan penjelasan konsep secara mendetail dengan menggiring pada pemahaman yang sesuai.

\section{PENUTUP}

Berdasarkan hasil dan pembahasan yang dipaparkan, implementasi model pembelajaran mampu meningkatkan skor penguasaan konsep elastisitas dan hukum Hooke pada siswa SMAN 5 Jambi. Skor penguasaan konsep siswa meningkat dari 42,31 pada saat pretest menjadi 57,01 pada saat posttest. Berdasarkan hasil uji beda dengan paired sample t-test diperoleh $\mathrm{t}=-4,901$ (sig. 0,000) sehingga dapat disimpulkan bahwa skor pretest dan posttest berbeda secara signifikan. Besar peningkatan skor tersebut berada dalam kategori sedang yang ditandai $N$-gain sebesar 0,255 . Berdasarkan nilai effect size (d) yang diperoleh yakni sebesar 0,930 yang menunjukkan bahwa implementasi model pembelajaran Problem Based Learning memberikan pengaruh yang kuat terhadap peningkatan konsep elastisitas dan hukum Hooke. Kendati peningkatan penguasaan konsep siswa ini masih berada dalam kategori rendah karena siswa belum terbiasa dengan model pembelajaran Problem Based Learning, namun penerapan pembelajaran ini sebaiknya tetap dilaksanakan karena memacu siswa untuk lebih aktif belajar dan membantu siswa memahami fisika secara lebih baik. Upaya-upaya yang perlu dilakukan oleh guru dalam pembelajaran fisika di antaranya seperti menyajikan fenomena yang mampu mengubah konsepsi siswa yang keliru, maupun menjelaskan secara detail konsep fisis untuk menggiring siswa menuju pemahaman yang benar. Hal tersebut penting karena sering kali konsep yang diyakini siswa tidak sesuai dengan konsep ilmiah maupun sesuai dalam konteks tertentu namun sering kali digeneralisasi dalam konteks yang tidak sesuai.

\section{DAFTAR PUSTAKA}

Adair, A. M. (2013). Student misconceptions about newtonian mechanics: Origins and solutions through changes to instruction. ProQuest Dissertations and Theses, 204. Retrieved from https://search.proquest.com/docview/1647196143? accountid=15272

Aguirre, J. M. (1988). Student preconceptions about vector kinematics. The Physics Teacher, 26(4), 212-216. https://doi.org/10.1119/1.2342490

Aguirre, J. M., \& Rankin, G. (1989). College students' conceptions about vector kinematics. Physics Education, 24(5), 290-294. https://doi.org/10.1088/00319120/24/5/310

Agustin, V. N. (2013). Peningkatan aktivitas dan hasil belajar siswa melalui model problem based learning (PBL). Journal of Elementary Education, 2(4), 36-44. 


\section{Formatif: Jurnal Ilmiah Pendidikan MIPA}

Vol. 9, No. 2, Juni 2019, pp. 107-116

p-ISSN: 2088-351X

e-ISSN: 2502-5457

DOI: http://dx.doi.org/10.30998/formatif.v9i2.3339

Antwi et al. (2011). Students' understanding of some concepts in introductory mechanics course: A study in the first year university students, $U E W, 1(1), 55-80$.

Azizah, R., Yuliati, L., \& Latifah, E. (2015). Kesulitan pemecahan masalah fisika pada siswa SMA. Jurnal Penelitian Fisika Dan Aplikasinya (JPFA), 5(2), 44-50. https://doi.org/10.26740/jpfa

Baksir, E. L., Mayub, A., \& Hanisa, P. D. (2017). Peningkatan aktivitas dan hasil belajar siswa serta kemampuan pemecahan masalah melalui model problem based learning pada konsep cahaya di kelas VIII.E SMPN 6 Kota Bengkulu. Jurnal Pembelajaran Fisika, 1(1), 64-72.

Bao, L. (2006). Theoretical comparisons of average normalized gain calculations. American Journal of Physics, 74 (10), 917-922. https://doi.org/10.1119/1.2213632

Berek, F. X., Sutopo, S., \& Munzil, M. (2016). Concept enhancement of junior high school students in hydrostatic pressure and archimedes law by predict-observeexplain strategy. Jurnal Pendidikan IPA Indonesia, 5(2), 230-238. https://doi.org/10.15294/jpii.v5i2.6038

Bernardi, R. A. (1994). Validating research results when cronbach's alpha is below 0.70 : A methodological procedure. Educational and Psychological Measurement, 54(3), 766-775.

Bezen, S., Bayrak, C., \& Aykutlu, I. (2016). Physics teachers' views on teaching the concept of energy. Eurasian Journal of Educational Research, (64), 109-124.

Close, H. G., Gomez, L. S., \& Heron, P. R. L. (2013). Student understanding of the application of Newton's second law to rotating rigid bodies. American Journal of Physics, 81(6), 458-470. https://doi.org/10.1119/1.4797457

Creswell, J. W. (2014). Research Design: Qualitative, Quantitative, and Mixed Methods Approaches (4th ed.). London: Sage Publication Ltd.

Docktor, J. L., \& Mestre, J. P. (2014). Synthesis of discipline-based education research in physics. Physical Review Special Topics - Physics Education Research, 10(2), 1-58. https://doi.org/10.1103/PhysRevSTPER.10.020119

Hake, R. R. (1998). Interactive-engagement versus traditional methods: A six-thousandstudent survey of mechanics test data for introductory physics courses. American Journal of Physics, 66(1), 64-74. https://doi.org/10.1119/1.18809

Hammer, D. (2000). Student resources for learning introductory physics. American Journal of Physics, 68(S1), S52-S59. https://doi.org/10.1119/1.19520

Hidayati, N. F., Akhsan, H., \& Syuhendri. (2014). Identifikasi miskonsepsi siswa kelas X pada materi elastisitas dan hukum Hooke di SMA Negeri 1 Indralaya. Jurnal Inovasi Dan Pembelajaran Fisika, 3(2), 1-9.

Janti, S. (2014). Analisis validitas dan reliabilitas dengan skala likert terhadap pengembangan SI/TI dalam penentuan pengambilan keputusan penerapan strategi planning pada industri garmen. In Seminar Nasional Aplikasi Sains dan Teknologi (SNAST) (Vol. 3, pp. A155-A160). https://doi.org/1979-911X

Jugueta, E. A. D., Go, C. K. C., \& Indias, J. M. M. (2012). Free fall misconceptions : A comparison between science and non-science university majors. Latin American Journal Physics Education, 6(Supplemento I), 2-5.

Kaniawati, I. (2017). Pengaruh simulasi komputer terhadap peningkatan penguasan konsep impuls-momentum siswa SMA. Jurnal Pembelajaran Sains, 1(1), 24-26.

Kartika, M. D., Santyasa, W., \& Warpala, W. (2014). Pengaruh model pembelajaran berbasis masalah. E-Journal Program Pascasarjana Universitas Pendidikan Ganesha, 4(1).

Leech, N. L., Barrett, K. C., \& Morgan, G. A. (2005). SPSS For Intermediate Statistics: Use and Interpretation (Second). London: Lawrence Erlbaum Associates. 


\section{Formatif: Jurnal Ilmiah Pendidikan MIPA}

Vol. 9, No. 2, Juni 2019, pp. 107-116

p-ISSN: 2088-351X

e-ISSN: 2502-5457

DOI: http://dx.doi.org/10.30998/formatif.v9i2.3339

Maryati, I. (2018). Penerapan model pembelajaran berbasis masalah pada materi pola bilangan di kelas VII Sekolah Menengah Pertama. Jurnal Mosharafa, 7(1), 63-74. Retrieved from http://e-mosharafa.org/index.php/mosharafa/article/view/mv7n1_7

Prasetyanti, N. M., Sari, D. N., \& Sajidan, S. (2016). Penerapan model pembelajaran problem based learning (PBL) untuk meningkatkan kemampuan proses berpikir kognitif siswa kelas XI MIPA-1 SMA Negeri 3 Surakarta Tahun Pelajaran 2015/2016. INKUIRI: Jurnal Pendidikan IPA, 5(2), 1-7.

Rimoldini, L. G., \& Singh, C. (2005). Student understanding of rotational and rolling motion concepts. Physical Review Special Topics - Physics Education Research, 1(1). https://doi.org/10.1103/PhysRevSTPER.1.010102

Robinson, S. J. (2014). Connecting the mathematical and conceptual views of angular momentum. Physics Education, 49(2), 144-148. https://doi.org/10.1088/00319120/49/2/144

Saifullah, A. M., Sutopo, S., \& Wisodo, H. (2017). Senior high school students' difficulties in solving impulse and momentum problems. Jurnal Pendidikan IPA Indonesia, 6(1), 1-10. https://doi.org/10.15294/jpii.v6i1.9593

Saputri, D. E., Taqwa, M. R. A., Aini, F. N., Shodiqin, I., \& Rivaldo, L. (2019). Pemahaman konsep mekanika: menentukan arah percepatan pendulum, sulitkah? Jurnal Pendidikan Fisika Dan Teknologi, 5(1), 110-117.

Setyorini, U., Sukiswo, S. E., \& Subali, B. (2011). Penerapan model problem based learning untuk meningkatkan kemampuan berpikir kritis siswa SMP. Jurnal Pendidikan Fisika Indonesia, 7, 52-56. https://doi.org/10.15294/jpfi.v7i1.1070

Singh, C., \& Rosengrant, D. (2016). Multiple-choice test of energy and momentum concepts, 607(2003). https://doi.org/10.1119/1.1571832

Sunaryo, Y. (2014). Model pembelajaran berbasis masalah untuk meningkatkan kemampuan berpikir kritis dan kreatif matematik siswa SMA Di Kota Tasikmalaya. Jurnal Pendidikan Dan Keguruan, 1(2), 41-51.

Suruchi, \& Rana, S. S. (2014). Test item analysis and relationship between difficulty level and discrimination index of test items in an achievement test in biology. Paripex - Indian Journal of Research, 3(6), 56-58.

Taqwa, M. R. A., \& Pilendia, D. (2018). Kekeliruan memahami konsep gaya. Apakah pasti miskonsepsi? Jurnal Inovasi Pendidikan Fisika Dan Integrasinya, 1 (2), 1-12.

Taqwa, M. R. A., Utami, Y. A., \& Rivaldo, L. (2019). Pengembangan buku siswa elektronik berbasis android pada materi suhu dan kalor untuk persiapan ujian nasional SMA/MA. Jurnal Briliant: Jurnal Riset Dan KonseptualBriliant: Jurnal Riset Dan Konseptual, 4(1), 225-234.

Thornton, R. K., \& Sokoloff, D. R. (1998). Assessing student learning of Newton's laws: The force and motion conceptual evaluation and the evaluation of active learning laboratory and lecture curricula. American Journal of Physics, 66(4), 338-352. https://doi.org/10.1119/1.18863

Tyas, R. (2017). Kesulitan penerapan problem based learning dalam pembelajaran matematika. Jurnal Tecnoscienza, 2(1), 43-52.

Velly, D. (2017). Peningkatan aktivitas dan hasil belajar siswa melalui penerapan model problem based learning dalam pembelajaran fisika di kelas XI MIPA 1 SMA Negeri 12 Pekanbaru. Jurnal Geliga Sains, 5(2), 88-94.

White, B. Y. (1983). Sources of difficulty in understanding newtonian dynamics. Cognitive Science, 7(1), 41-65. https://doi.org/10.1016/S0364-0213(83)80017-2

Yulianawati, D., Muslim, Hasanah, L., \& Samsudin, A. (2018). A case study of analyzing 11 thgraders' problem solving ability on heat and temperature topic. Journal of Physics: Conference Series, 1013(1), 0-7. 